\title{
BMJ open Time trend in hospitalised chronic lower respiratory diseases among Danish building and construction workers, 1981-2009: a cohort study
}

\author{
Finn Tüchsen, ${ }^{1}$ Harald Hannerz, ${ }^{2}$ Ellen Fisher Mølgaard, ${ }^{3}$ Charlotte Brauer, ${ }^{3}$ \\ Lilli Kirkeskov ${ }^{3}$
}

To cite: Tüchsen $F$, Hannerz H, Mølgaard EF, et al. Time trend in hospitalised chronic lower respiratory diseases among Danish building and construction workers, 1981-2009: a cohort study. BMJ Open 2012;2:e001761. doi:10.1136/bmjopen-2012001761

- Prepublication history for this paper are available online. To view these files please visit the journal online (http://dx.doi.org/10.1136/ bmjopen-2012-001761).

Received 7 July 2012 Accepted 28 September 2012

This final article is available for use under the terms of the Creative Commons Attribution Non-Commercial 2.0 Licence; see http://bmjopen.bmj.com

${ }^{1}$ Nordvej 16a, DK-4000 Roskilde, Denmark ${ }^{2}$ National Research Institute for the Working Environment, Copenhagen, Denmark ${ }^{3}$ Department of Occupational and Environmental Medicine, Bispebjerg Hospital, Copenhagen, Denmark

Correspondence to Dr Finn Tüchsen, ft@privat.dk

\section{ABSTRACT}

Objectives: To show trends in age-standardised hospital admission ratios (SHR) for chronic lower respiratory diseases, estimated for Danish construction workers over three time periods (1981-1990, 1991-2000, 2001-2009).

Design: Within consecutive cohorts of all male building and construction workers in Denmark, selected occupations: bricklayers, carpenters, electricians, painters, plumbers and 'other construction workers' were followed up for hospitalisation due to chronic lower respiratory diseases. SHR was calculated for each occupation and time period. Time trend was calculated for construction workers at large using Poisson regression.

Setting: Denmark.

Participants: All gainfully employed male building and construction workers aged 20 or more.

Primary and secondary outcome measures: Age-standardised and gender-standardised hospitalisation ratios (SHR).

Results: The number of hospitalised construction workers at large was reduced from 1134 in the first 10 -year period to 699 in the last 9 -year period. Among all Danish males, it was, however, even more reduced as reflected in the expected number that was down from 1172 to 617 . Hence, SHR increased from 97 during 1981-1990, 100 during 1991-2000 to 113 during 2001-2009. It means that SHR increased with an average rate of $0.76 \%$ per year $(95 \% \mathrm{Cl} 0.28$ to 1.24) during the study period. A low SHR $=72(95 \% \mathrm{Cl}$ 60 to 87) was found among carpenters in 1981-1990. From 2001 to 2009, high SHRs were found among painters (SHR=147; $95 \% \mathrm{Cl} 111$ to 192) and plumbers (SHR=132; 95\% Cl 101 to 171). In general, the selected groups of construction workers had, however, a low or average SHR due to chronic lower respiratory diseases.

Conclusions: The number of hospitalised workers, suffering from chronic lower respiratory diseases, was reduced over time for construction workers, but for all economically active men, it was reduced even more. Therefore, SHR due to chronic lower respiratory diseases increased over time in the construction industry at large.

\section{ARTICLE SUMMARY}

Article focus

- The focus of the study was to show trends in age-standardised hospital admission ratios (SHR) for chronic lower respiratory diseases, estimated among Danish construction workers over three time periods (1981-1990, 1991-2000, 2001-2009).

- Exposure to dust, gases, vapours and fumes was known to cause chronic lower respiratory diseases, but the incidence of these diseases and the change over time was not known for various dust-exposed building construction professions.

- The number of construction workers hospitalised due to chronic lower respiratory diseases was reduced over time for construction workers, but for all economically active men, it was reduced even more.

Key messages

- A decreased standardised hospitalisation ratio (SHR) due to chronic lower respiratory diseases was found in 1991-2000 among carpenters. From 2001 to 2009, a high SHR was found among painters, plumbers and 'other construction workers'. SHR increased significantly over time among 'construction workers at large'.

- The highest SHR's were found among workers aged 45 or more at baseline.

Strengths and limitations of this study

- Strength of our study design is that it covers the entire nation and therefore neglects urbanisation differences and that that we are able to follow people over a 29-year period.

- Strength is also that hardly any worker is lost to follow-up because civil registration files and hospital records are complete. We also consider it as strength that our cases are hospital-discharge diagnoses rather than self-reported illness.

- The use of hospital discharge cases is, however, also a limitation because admission criteria change over time, so only relative measures such as SHR are reliable risk measures. 


\section{INTRODUCTION}

Chronic obstructive pulmonary disease (COPD) is a major cause of chronic morbidity and mortality throughout the world. COPD is currently the fourth leading cause of death in the world and incidence is increasing. COPD is a disease characterised by airflow limitation that is not fully reversible. ${ }^{1}$ A recent study based on 4757 patients from 155 general practices in two (out of 12) counties estimated the overall COPD prevalence in the Danish population to be $9 \% .^{2}$ The value is in consistence with prevalence rates found in Spain $(10.2 \%)^{3}$ and Norway $(11.6 \%){ }^{4}$

The major environmental factor that causes COPD is tobacco smoke (both active ${ }^{5}$ and passive smoking ${ }^{6}$ ). Also heavy exposure to occupational dusts and chemicals (vapours, irritants and fumes), and indoor/outdoor air pollution are known risk factors. ${ }^{6-17}$ When the occupational exposures are sufficiently intense or prolonged, they can cause COPD independently of cigarette smoking and can in addition increase the risk of the disease in the presence of concurrent cigarette smoking. ${ }^{16}$ The lung function deteriorate with accumulating occupational exposure to dust. ${ }^{17}$ Furthermore, ongoing occupational fume exposure has been shown to affect the rate of decline in lung function among men with early COPD over 5 years of follow-up. ${ }^{7}$ Therefore, a substantial proportion of COPD cases cannot be explained by tobacco smoke alone. ${ }^{18}$ A recent Danish review ${ }^{19}$ concludes: 'there is strong evidence for a causal association between various types of occupational exposures and COPD'. COPD should be considered as a potentially work-related condition.

Occupational exposure to dust and chemicals and a higher risk of COPD, is found in several manual occupations. An excess risk of COPD is found among farmers, cotton textile workers, wood carpenters, bakers and mill workers who are exposed to organic dust. ${ }^{8} 10$ However, exposure to inorganic material has also been associated with airway obstruction among welders, foundry workers, asphalt workers and coal miners. 891213

Previous studies have measured dust concentrations in the construction industry in a level that may constitute a hazard for developing chronic lower respiratory diseases. In the 1970s, the Swedish Construction Industry's Organization for Working Environment, Safety and Health described high peaks of dust exposure in the work for concrete workers, painters, plumbers, insolators and electricians. ${ }^{14} 20$ A Danish study from the 1980 s found examples where workers in the construction industry were exposed to $1.2-25.5 \mathrm{mg} / \mathrm{m}^{3}$ respirable dust (limit $5 \mathrm{mg} / \mathrm{m}^{3}$ ). ${ }^{21}$ More recent studies have measured respirable dust in construction industry with concentrations between 2 and $3 \mathrm{mg} / \mathrm{m}^{3}$ during different concrete tasks. ${ }^{1522}$ The Institute for Occupational Safety and Health of the German Social Accident Insurance measured respirable dust in different work processes within the construction industry and showed concentrations for bricklaying at $0.67 \mathrm{mg} / \mathrm{m}^{3}$, grinding (painters) at $1.24 \mathrm{mg} / \mathrm{m}^{3}$, and drilling at $1.07 \mathrm{mg} / \mathrm{m}^{3}$ (concrete workers) (BGIA-report). ${ }^{23}$ These studies show that there has been a significant dust exposure in several professions within the construction industry with the highest exposure among concrete workers. It is often assumed that the dust exposure today is lower but we have not found any up-to-date measurements to prove this.

Two studies of tunnel workers and several studies of building and construction workers showed an increased risk of COPD. ${ }^{8} 11{ }^{24-26}$ We found no studies that followed the time trend in relative risk of COPD owing to occupational exposure.

Hence, the aim of the present study was to identify trends in age-standardised hospital admission ratios (SHR) for COPD (international classification of diseases version 8 (ICD-8))/chronic lower respiratory diseases (ICD-10), estimated for all Danish construction workers and specific construction occupations (bricklayers, carpenters, electricians, painters, plumbers and others combined), over three time periods (1981-1990, 1991-2000, 2001-2009). This study should be considered descriptive because we have no individual data to adjust for smoking habits.

\section{MATERIALS AND METHODS}

Data for the present study were extracted from the Occupational Hospitalisation Register (OHR). ${ }^{27}$ OHR is a research database obtained through a record-linkage between three national registers - the civil registration system, the national patient register and the employment classification module. Currently, the OHR includes every person who has been economically active and an inhabitant of Denmark sometime after 1980.

The national patient register has existed since 1977 and contains data from all hospitals in Denmark (more than 99\% of all admissions). From 1977 to 1994, the register only included inpatients. But from 1995 it also covers outpatients and emergency ward visits. In the time period 1977-1993, the diagnoses were coded according to ICD-8. Since 1994, they have been coded according to ICD-10.

The Civil Registration System contains information on gender, addresses and dates of birth, death and migrations for every person who is or has been an inhabitant of Denmark sometime between 1968 and present time.

Since 1975, Statistics Denmark register a person's occupation and industry annually in the employment classification module. From 1975 to 1993, the occupations were coded in accordance with NYSTGR, an extended version of ISCO-68 (the 1968 version of the Standard Classification of Occupations), while the industries were classified by DSE77, a national version of ISIC-68 (the International Standard Industrial Classification of All Economic Activities). Since 1993, the occupations are coded according to DISCO-88, a national version of ISCO-88. In 1993-2002, the industries were coded according to DB93, a national version of NACE (the statistical classification of economic activities in the European Community). In 2003-2006, they were coded according to DB03, and since 2007, they are coded according to 
DB07; these classifications are national versions of NACE. ${ }^{27}$ The occupation classified was the one, which gave the highest income during the year before baseline.

\section{Follow-up and statistical analysis}

All economically active men in Denmark aged 20-59 in January 1981, 1991 and 2001 were classified according to their most important occupation and industry in 1980, 1990 and 2000, respectively. These cohorts were followed up for first recorded hospital discharge owing to chronic lower respiratory diseases as a principal diagnosis, from 1981 to 1990,1991 to 2000 and 2001 to 2009 , respectively. For any given individual, the follow-up ended at the date of the hospital admission due to chronic lower respiratory diseases, death or migration or at the end of the follow-up period whichever came first. All economically active men were used as standard population and standardised hospitalisation ratios (SHR) for chronic lower respiratory diseases was calculated for the construction industry at large and for each of the following occupational groups: bricklayers, carpenters, electricians, painters and plumbers. SHRs were standardised for age and time period, where age-standardised SHR were calculated for three periods (1981-1990, 1991-2000, 2001-2009) using 5-year age strata based on the person's age when entering each period. Thus, the observed number of hospitalisation for chronic lower respiratory diseases for the construction workers were compared with the expected number of hospitalisation for chronic lower respiratory diseases for All Danish males for each 5-year age strata, to obtain the SHR for each time period. The same method was used for All Construction Workers and for each subgroup (bricklayers, carpenters, electricians, painters, plumbers and others combined). A person was regarded as a COPD/chronic lower respiratory diseases patient if he had a principal discharge diagnosis in the ICD-8 interval 490-493 (bronchitis, emphysema and asthma (COPD)) or in the ICD-10 interval J40-J47 (chronic lower respiratory diseases).

For the construction industry at large, we also calculated SHR for chronic lower respiratory diseases by age group. We obtained the SHR for workers in, for example, the age group 20-24 years by (1) adding the observed number of cases in the time periods 1981-1990, 19912000 and 2001-2009 among those who were 20-24 years of age at baseline in these respective time periods; (2) dividing the above sum by the sum of the corresponding expected numbers; and (3) multiplying this ratio by 100. (If the rates among the 20-24-year-old construction workers were equal to those among the 20-24-year-old in the standard population (all economically active men in Denmark) then the SHR would be equal to 100.)

For the SHRs, we estimated $95 \%$ CI based on the assumption that the observed number of cases followed a Poisson distribution. We calculated exact intervals when the observed number of cases was less than 100 . Otherwise, we used the propagation of error formulas and normal approximation to form a $95 \%$ CI around the logarithm of the SHR, which we then transformed into a $95 \%$ CI around the SHR.

We used Poisson regression to estimate the average annual change rate in SHR for the construction industry at large. As a regressor we used a variable $\mathrm{T}$, which was set to 0 among the observations from the time period 1981-1990, $\mathrm{T}=10$ among the ones from the time period 1991-2000 and so on. The logarithm of the age-standardised and time-period-standardised expected number of cases was used as offset.

For each time period $\mathrm{k}$, the SHR for an occupational category i was calculated through the following formula:

$$
\mathrm{SHR}_{\mathrm{ik}}=100 \times \frac{\sum_{j} \mathrm{OBS}_{\mathrm{ijk}}}{\sum_{j} \frac{\mathrm{OBS}_{. \mathrm{jk}}}{\text { PYRS }_{. \mathrm{jk}}} \times \mathrm{PYRS}_{\mathrm{ijk}}}
$$

where $\mathrm{OBS}_{\mathrm{ijk}}$ is the observed number of cases and PYRS $_{\mathrm{ijk}}$ is the number of person years at risk in occupational category $\mathrm{i}$, age category $\mathrm{j}$ and time period $\mathrm{k}$, while $\mathrm{OBS}_{. j \mathrm{k}}$ and PYRS $\mathrm{jk}_{\mathrm{jk}}$ are the corresponding numbers in the standard population.

For a given occupational category i, the SHR for age category $\mathrm{j}$ was calculated through the formula:

$$
\mathrm{SHR}_{\mathrm{ij}}=100 \times \frac{\sum_{\mathrm{k}} \mathrm{OBS}_{\mathrm{ijk}}}{\sum_{\mathrm{k}} \frac{\mathrm{OBS}_{\mathrm{jk}}}{\mathrm{PYRS}_{. j \mathrm{k}}} \times \mathrm{PYRS}_{\mathrm{ijk}}}
$$

\section{RESULTS}

Table 1 shows the SHRs due to chronic lower respiratory diseases among construction workers from different occupations. The number of hospitalised construction workers at large was reduced from 1134 in the first 10-year period to 699 in the last 9-year period. Among all Danish males, it was, however, even more reduced as reflected in the expected number that was down from 1171.8 to 616.6. Hence, SHR increased from 97 during 1981-1990, 100 during 1991-2000 to 113 during 2001-2009. This increase was due to increasing SHRs in two groups: painters and 'other constructionworkers'.

A test for trend showed for the construction industry at large, that SHR increased with an average rate of $0.76 \%$ per year (95\% CI 0.28 to 1.24 ) during the study period.

We found a statistically significant increase of SHR among constructions workers in total, and among painters, plumbers and 'other construction workers' but only for the period 2001-2009. During 1981-1990, SHR was significantly low for carpenters.

Table 2 shows the SHR due to chronic lower respiratory diseases among male construction workers for the three follow-up periods combined. SHR were increased for age groups more than 45 years, but only significantly for subjects aged 45-59 years. When looking only at the period 2001-2009, the SHR due to chronic lower 
Table 1 Standardised hospitalisation ratios (SHR) due to chronic lower respiratory diseases among male Danish construction workers and 95\% Cl, 1981-1990, 1991-2000 and 2001-2009

\begin{tabular}{|c|c|c|c|c|c|c|c|}
\hline Occupation & Period & Persons & PYRS & Observed & Expected & SHR & $95 \% \mathrm{Cl}$ \\
\hline \multirow[t]{3}{*}{ Bricklayers } & 1981-1990 & 13980 & 134494 & 93 & 100.5 & 93 & 75 to 113 \\
\hline & 1991-2000 & 9050 & 88036 & 94 & 78.1 & 120 & 97 to 147 \\
\hline & 2001-2009 & 9352 & 81828 & 47 & 44.8 & 105 & 77 to 140 \\
\hline \multirow[t]{3}{*}{ Carpenters } & $1981-1990$ & 23829 & 229313 & 109 & 150.7 & 72 & 60 to 87 \\
\hline & $1991-2000$ & 18327 & 178339 & 125 & 141.7 & 88 & 74 to 105 \\
\hline & 2001-2009 & 27381 & 240286 & 98 & 116.6 & 84 & 68 to 102 \\
\hline \multirow{3}{*}{ Electricians } & 1981-1990 & 12929 & 124888 & 58 & 67.5 & 86 & 65 to 111 \\
\hline & 1991-2000 & 12865 & 125392 & 73 & 88.4 & 83 & 65 to 104 \\
\hline & 2001-2009 & 16087 & 141978 & 48 & 59.0 & 81 & 60 to 108 \\
\hline \multirow[t]{3}{*}{ Painters } & $1981-1990$ & 8983 & 86692 & 64 & 77.8 & 82 & 63 to 105 \\
\hline & $1991-2000$ & 7857 & 75992 & 72 & 70.6 & 102 & 80 to 128 \\
\hline & 2001-2009 & 7982 & 69893 & 56 & 38.0 & 147 & 111 to 192 \\
\hline \multirow[t]{3}{*}{ Plumbers } & $1981-1990$ & 9853 & 95433 & 64 & 63.7 & 100 & 77 to 128 \\
\hline & 1991-2000 & 8759 & 85372 & 55 & 66.7 & 83 & 62 to 107 \\
\hline & 2001-2009 & 11190 & 98191 & 59 & 44.6 & 132 & 101 to 171 \\
\hline \multirow[t]{3}{*}{ Other construction workers } & 1981-1990 & 85783 & 823920 & 746 & 711.6 & 105 & 98 to 113 \\
\hline & $1991-2000$ & 77836 & 749332 & 667 & 638.7 & 104 & 97 to 113 \\
\hline & 2001-2009 & 69479 & 609054 & 391 & 313.7 & 125 & 113 to 138 \\
\hline \multirow[t]{3}{*}{ All construction workers } & $1981-1990$ & 155357 & 1494739 & 1134 & 1171.8 & 97 & 91 to 103 \\
\hline & $1991-2000$ & 134694 & 1302464 & 1086 & 1084.3 & 100 & 94 to 106 \\
\hline & 2001-2009 & 141471 & 1241228 & 699 & 616.6 & 113 & 105 to 122 \\
\hline
\end{tabular}

respiratory diseases among all male construction workers was 106 (95\% CI 92 to 121) among the 20-39-year-olds and 117 (95\% CI 107 to 128) among the 40-year to 59-year old.

\section{DISCUSSION}

Our data suggest that the number of hospitalised chronic lower respiratory diseases patients decrease over time, but not as fast among construction workers as among all economically active men. We found significantly high SHRs' among painters, plumbers and 'other construction workers combined', from 2001 to 2009 as well as for construction workers at large. The increased SHRs tend to be found among patients aged 45 or more. Most noteworthy is, however, an increasing time trend in SHR in the construction industry at large.

Table 2 Standardised hospitalisation ratios (SHR) due to chronic lower respiratory diseases among male construction workers with $95 \% \mathrm{Cl}$ by age group

\begin{tabular}{lllllr}
\hline Age group & Persons & Obs. & Exp. & SHR & \multicolumn{1}{c}{$\mathbf{9 5 \%}$ Cl } \\
\hline $20-24$ & 60789 & 198 & 197.5 & 100 & 87 to 115 \\
$25-29$ & 63236 & 212 & 211.5 & 100 & 88 to 115 \\
$30-34$ & 64831 & 217 & 233.0 & 93 & 82 to 106 \\
$35-39$ & 62081 & 258 & 268.8 & 96 & 85 to 108 \\
$40-44$ & 55376 & 301 & 317.8 & 95 & 85 to 106 \\
$45-49$ & 47907 & 465 & 418.1 & 111 & 102 to 122 \\
$50-54$ & 42680 & 552 & 532.4 & 104 & 95 to 113 \\
$55-59$ & 34622 & 716 & 693.6 & 103 & 96 to 111 \\
\hline
\end{tabular}

Chronic lower respiratory diseases often reduce the lung capacity among workers to half or less before they refer themselves to a physician. The real incidence is therefore likely to be higher than the incidence of hospitalised chronic lower respiratory diseases patients, but we have no reason to believe that the undiagnosed proportion is higher among those occupied in dusty construction work. On the contrary, workers in these occupations need a good lung capacity, and a chronic lower respiratory diseases diagnosis may therefore be suspected earlier. If so, we may overestimate the SHR among construction workers.

We used the ICD-8 code '490-493' (asthma, emphysema and bronchitis) to identify hospital cases. Since this definition is broader than the Gold definition of COPD, some of our cases are not COPD patients in a clinical definition. This dilution weakness tends to bias our results towards unity. It is also a weakness of our study that exposure is only indicated by occupation. Within the same occupation, there may be different work tasks and thus various exposures to dust. This dilution may also bias the results towards unity.

Chronic lower respiratory diseases severe enough to require hospitalisation associated with occupational hazards (dust, fumes, etc) usually develop after 20-30 years of exposure. We do not include people older than 59 at baseline. Latency time, especially for emphysema, may be too long for a discharge to occur before the end of follow-up. If so, our 10-year follow-up periods may be too short and thus bias the SHR towards unity. It is an important strength that the occupation is measured as the occupation providing the highest income during the year before 
Table 3 Smoking prevalence among all 16-70-year-old male Danish employees and all male construction workers from the Danish Working Environment Cohort Study 1990, 1995, 2000 and 2005

\begin{tabular}{|c|c|c|c|c|c|}
\hline & Year & Persons & Smokers & Per cent & $95 \% \mathrm{Cl}$ \\
\hline All Danish & 1990 & 3097 & 1518 & 49.0 & 47.3 to 50.8 \\
\hline \multirow[t]{3}{*}{ employees } & 1995 & 2926 & 1272 & 43.5 & 41.7 to 45.3 \\
\hline & 2000 & 2819 & 1127 & 40.0 & 38.2 to 41.8 \\
\hline & 2005 & 2487 & 749 & 30.1 & 28.3 to 31.9 \\
\hline Construction & 1990 & 320 & 178 & 55.6 & 50.2 to 61.1 \\
\hline \multirow[t]{3}{*}{ workers } & 1995 & 264 & 118 & 44.7 & 38.7 to 50.7 \\
\hline & 2000 & 276 & 114 & 41.3 & 35.5 to 47.1 \\
\hline & 2005 & 280 & 87 & 31.1 & 25.7 to 36.5 \\
\hline
\end{tabular}

baseline instead of a point estimate. This is especially important for building and construction workers who are often doing other jobs or are unemployed in the winter. In principle, an even better risk estimate can be obtained by excluding all workers with less than 5 years seniority but previous analysis has shown that the gain in precision is often lost owing to lower power. However, skilled workers tend to stay in the same occupations even though they often change employer. If people are skilled and they have worked in the trade for a 10-year period, they may also have performed the same tasks for a much longer period.

In this study, we have no individual data on smoking prevalence. It is a limitation of our study because smoking is an important risk factor for COPD. During 1970-1989, smoking habits among Danish male skilled workers aged 16+ versus all Danish men (in parenthesis) were measured to be $59.1 \%(46.6 \%)$ in $1970,56.2 \%$ $(45.5 \%)$ in $1975,54.8 \%(43.9 \%)$ in $1980,54.2 \%(41.8 \%)$ in $1985 .{ }^{28}$ Hence, the true dust-related SHR is likely to be slightly lower than reported in the present study.

Smoking data from the Danish Working Environment Cohort Study ${ }^{29}$ collected during each of the years 1990, 1995, 2000 and 2005 shows that smoking has been reduced considerably (table 3 ). The relative importance of dust to smoking has therefore increased.

Strength of our study design is that it covers the entire nation and therefore neglects urbanisation differences. Strength is also that hardly any worker is lost to follow-up because civil registration files and hospital records are complete. We also consider it as strength that our cases are hospital-discharge diagnoses rather than self-reported illness. Finally, it is strength that we are able to follow people over a 29-year period.

It takes many years of exposure to dust and a considerable latency time to develop hospitalising chronic lower respiratory disease cases. Chronic lower respiratory diseases occurring prior to 45 years of age are usually in individuals with increased susceptibility due to asthma, emphysema, or small-airways disease. In this study, we showed an increased risk of hospitalisation due to chronic lower respiratory diseases after the age of 45 compared to the general population. This may indicate that dust increased the risk of hospitalisation due to chronic lower respiratory diseases before 1995 but not since then.
The present study showed that painters, plumbers and other construction workers in combination had substantially increased SHRs compared to all Danish males during the most recent time period at the same time as the smoking pattern was average compared to all males.

Protection against dust has been a prioritised field within occupational health for more than half a century. The awareness of the dust hazard is relatively high among building construction workers, and the labour inspection service close down dusty work processes. There are many possibilities to replace dusty processes with other less dust-producing methods (such as wet cutting) and new tools to collect dust at the source. However, wearing masks is inconvenient, it inhibits breathing and is warm and unpleasant. It also takes time and is expensive. Hence, it is still common to see dusty processes carried out by construction workers without protective masks. Furthermore, there are more quartzholding concrete buildings to repair. Hand-held tools, such as angle grinders, pneumatic and electric drills, are used more and they are more powerful, that is, they can disintegrate more concrete into dust per time unit. The respirable fraction of the dust is also likely to have increased but it is problematic that no recent measure of dust exposure in various construction occupations is available. Therefore, it is still necessary to focus on these issues.

In conclusion, we found that hospitalisation due to chronic lower respiratory diseases decreases, not so much for construction workers, however, as for other economically active men. For the construction industry at large, SHR increases over time.

Contributors LK, CB, FT and HH designed the study. FT and $\mathrm{HH}$ updated the Occupational Hospitalization Register. HH statistically analysed and drafted the Methods section. FT made the first and the final draft. All authors contributed with text, ideas and critical revisions. All authors have read and approved the final draft.

Funding This study was made possible by grant No. 21-2010-09 from the Danish Working Environment Research Fund.

\section{Competing interests None.}

Permissions OHR was established with permission from the Minister of labour, the Minister of economical affairs and the Minister of health, back in the mid-1980s. Statistics Denmark and the National Board of Health are responsible for data security. The Danish Working Environment Research 
Institute is the only user of the data and gives permission to co-researchers. According to Danish law, research based on anonymous statistical data need no permission from ethical committees.

Provenance and peer review Not commissioned; externally peer reviewed.

Data sharing statement Contact National Research Centre for the Working Environment, Copenhagen for access to data from the Occupational Hospitalization Register.

\section{REFERENCES}

1. Pauwels R. Global initiative for chronic obstructive lung diseases (GOLD): time to act. Eur Respir J 2001;18:901-2.

2. Hansen JG, Pedersen L, Overvad K, et al. The Prevalence of chronic obstructive pulmonary disease among Danes aged 45-84 years: population-based study. COPD 2008;5:347-52.

3. Miravitlles M, Soriano JB, Garcia-Rio F, et al. Prevalence of COPD in Spain: impact of undiagnosed COPD on quality of life and daily life activities. Thorax 2009;64:863-8.

4. Bakke P, Eide GE, Hanoa R, et al. Occupational dust or gas exposure and prevalences of respiratory symptoms and asthma in a general population. Eur Respir J 1991;4:273-8.

5. Godtfredsen NS, Vestbo J, Osler M, et al. Risk of hospital admission for COPD following smoking cessation and reduction: a Danish population study. Thorax 2002;57:967-72.

6. Hnizdo E, Sullivan PA, Bang KM, et al. Association between chronic obstructive pulmonary disease and employment by industry and occupation in the US population: a study of data from the Third National Health and Nutrition Examination Survey. Am J Epidemiol 2002; 156:738-46.

7. Harber P, Tashkin DP, Simmons M, et al. Effect of occupational exposures on decline of lung function in early chronic obstructive pulmonary disease. Am J Respir Crit Care Med 2007;176:994-1000.

8. Mastrangelo G, Tartari M, Fedeli U, et al. Ascertaining the risk of chronic obstructive pulmonary disease in relation to occupation using a case-control design. Occup Med (Lond) 2003;53:165-72.

9. Randem BG, Ulvestad B, Burstyn I, et al. Respiratory symptoms and airflow limitation in asphalt workers. Occup Environ Med 2004;61:367-9.

10. Tüchsen F, Hannerz H. Social and occupational differences in chronic obstructive lung disease in Denmark 1981-1993. Am J Ind Med 2000;37:300-6.

11. Ulvestad B, Bakke B, Melbostad E, et al. Increased risk of obstructive pulmonary disease in tunnel workers. Thorax 2000;55:277-82.

12. Erkinjuntti-Pekkanen R, Slater $\mathrm{T}$, Cheng $\mathrm{S}$, et al. Two year follow up of pulmonary function values among welders in New Zealand. Occup Environ Med 1999;56:328-33.

13. Attfield MD, Kuempel ED. Mortality among U.S. underground coal miners: a 23-year follow-up. Am J Ind Med 2008;51:231-45.
14. Lee WJ, Baris D, Järvholm B, et al. Multiple myeloma and diesel and other occupational exposures in Swedish construction workers. Int J Cancer 2003;107:134-8.

15. Tjoe Nij E, Burdorf A, Parker J, et al. Radiographic abnormalities among construction workers exposed to quartz containing dust. Occup Environ Med 2003;60:410-17.

16. Kauffmann F, Drouet $\mathrm{D}$, Lellouch $\mathrm{J}$, et al. Occupational exposure and 12-year spirometric changes among Paris area workers. $\mathrm{Br} \mathrm{J}$ Ind Med 1982;39:221-32.

17. Ulvestad B, Bakke B, Eduard W, et al. Cumulative exposure to dust causes accelerated decline in lung function in tunnel workers. Occup Environ Med 2001;58:663-9.

18. Eisner MD, Anthonisen N, Coultas D, et al. An official American Thoracic Society public policy statement: Novel risk factors and the global burden of chronic obstructive pulmonary disease. $A m \mathrm{~J}$ Respir Crit Care Med 2010;182:693-718.

19. Aasen TB, Blanc PD, Brisman J, et al. Occupational COPD. Correlations between Chronic Obstructive Pulmonary Disease and various types of physical and chemical exposures at work. Copenhagen: Danish Working Environment Research Fund, 2009:72.

20. Anonymous. Environmental description of occupations within the construction industry Report from Bygghälsan. In Swedish. Stockholm: Bygghälsan, 1977.

21. Brendstrup $T$, Hasle $P$, Jensen $E$, et al. [The risk of silicosis from building site dust.] Silikoserisiko ved byggepladsstøv. In Danish. Ugeskr Laeger 1990;152:1882-6. 1990/06/25).

22. Peters S, Thomassen $\mathrm{Y}$, Fechter-Rink E, et al. Personal exposure to inhalable cement dust among construction workers. J Environ Monit 2009;11:174-80.

23. Ute Bagschick MB, Chromy W, Dahmann D, et al. Exposure to quartz at the workplace BGIA-Report. Berlin: Institut für Arbeitsschutz der Deutshen Gesetzlichen Umfallversicherung, 2008.

24. Dement JM, Welch L, Ringen K, et al. Airways obstruction among older construction and trade workers at Department of Energy nuclear sites. Am J Ind Med 2010;53:224-40.

25. Bergdahl IA, Toren K, Eriksson K, et al. Increased mortality in COPD among construction workers exposed to inorganic dust. Eur Respir $J$ 2004;23:402-6.

26. Tüchsen F, Hannerz H, Spangenberg S. Mortality and morbidity among bridge and tunnel construction workers who worked long hours and long days constructing the Great Belt Fixed Link. Scand $J$ Work Environ Health 2005;31:22-6.

27. Tüchsen F, Bach E. Occupation, morbidity, and hospital admission. Scand J Public Health 2011;39:141-6.

28. Nielsen PE, Sørensen JF. Change in smoking habits in the Danish population 1988-1993. In Danish with a summary in English. (Danskernes rygevaner 1988-1993. En opfølgning af tidligere befolkningsundersøgelser). Ugeskr laeger, 1995;157:3451-6.

29. Burr H, Bjorner JB, Kristensen TS, et al. Trends in the Danish work environment in 1990-2000 and their associations with labor-force changes. Scand J Work Environ Health 2003;29:270-9. 